\title{
EDUCAÇÃO INCLUSIVA: DAS DIFERENÇAS COMO POSSIBILIDADES (DA TEORIA À PRÁTICA)
}

Luiz Carlos Mariano da Rosa1

marianodarosaletras@terra.com.br

\section{Aspectos Introdutórios}

A legislação que acena com um sistema educacional inclusivo põe em relevo um conjunto de problemáticas relacionadas à existência dos portadores $\left(?^{2}\right)$ de deficiência $^{3}$, transtornos globais do desenvolvimento (TGD) e altas habilidades ou superdotação, especificamente, demandando da coletividade o enfrentamento das questões que envolvem a sua integração, adaptabilidade e desenvolvimento em uma estruturalidade (a saber, a sociedade), à medida que sublinha a necessidade que implica a construção de uma proposta pedagógica capaz de complementar, suplementar e substituir os serviços geralmente disponibilizados no referido arcabouço, convergindo para possibilitar o acesso aos recursos especiais que o processo formativo-educacional reivindica no sentido de viabilizar, no tocante a condição que se lhe imputa o contexto sociocultural, o compartilhamento dos educandos em questão com o horizonte que encerra a descoberta, a utilização e a ampliação das suas potencialidades, tanto quanto, em suma, a emergência das suas aptidões.

Autismo. Deficiência mental. Deficiência auditiva. Deficiência visual. Problemas motores. Perturbações emocionais graves. Distúrbios de comportamento. Dificuldades de aprendizagem. Problemas de comunicação. Multideficiência. Outros

\footnotetext{
1. Escritor e poeta, pesquisador e ensaísta; Autor de O Todo Essencial, Universitária Editora, Lisboa, Portugal, e, entre outros, Quase Sagrado (em edição); Graduado em Filosofia pelo Centro Universitário Claretiano de Batatais (CEUCLAR/SP) e Pós-Graduando em Filosofia pela Universidade Gama Filho (UGF/RJ); Diretor-Fundador, Coordenador e Pesquisador do Espaço Politikón Zôon-Educação, Arte e Cultura (CNPJ nº 10.642.249/0001-54), e Empreendedor Sociocultural.
}

2 . "A deficiência não pode ser vista como uma qualidade presente no organismo da pessoa ou no seu comportamento. Em vez de circunscrever a deficiência nos limites corporais da pessoa deficiente, é necessário incluir as reações de outras pessoas como parte integrante e crucial de fenômeno, pois são essas reações que, em última instância, definem alguém como deficiente ou não-deficiente" (MAZZOTTA, 1987, p. 67-68).

3 . "Conjunto de problemáticas relacionadas com o autismo, a deficiência mental, a deficiência auditiva, a deficiência visual, os problemas motores, as perturbações emocionais graves, os problemas de comportamento, as dificuldades de aprendizagem, os problemas de comunicação, a surdo-cegueira, a multideficiência e outros problemas de saúde (Aids, epilepsia, diabetes etc.)" (CORREIA, 2006, p. 249 , grifos do autor). 
(Aids, epilepsia, diabetes, etc.). À diversidade em questão se impõe um arcabouço de necessidades diferenciadas de um processo de inclusão que não se esgota na simples disponibilização de matrículas nas instituições escolares, que tende a realçar de modo negativo as diferenças se não for empreendida uma reordenação estrutural que contemple aspectos organizativos, curriculares e profissionais e possibilite a participação do educando em questão, tendo em vista que um processo formativoeducacional que acena com as suas especificidades converge não somente para assegurar o seu direito de acesso ao ambiente escolar mas para o êxito do trabalho, não permitindo que o educando especial se mantenha "excluído" dentro do estabelecimento de ensino.

Às limitações, envolvendo os aspectos psicológicos, fisiológicos, anatômicos e sociais, no tocante às necessidades especiais, se impõe uma graduação que acena com a questão da adaptabilidade, à medida que convergem para engendrar um determinado grau de dificuldade que caracteriza a relação intersubjetiva e a co-participação da sociabilidade, configurando uma decomposição que guarda referência com três grupos, a saber, aquele que abrange a perda ou anormalidade de uma estrutura ou função psicológica, fisiológica ou anatômica que gere incapacidade para o desempenho de atividade (deficiência), outro que corresponde à perda ou anormalidade em questão sob a acepção de um problema que ocorreu ou se estabilizou durante um período de tempo suficiente para não permitir recuperação ou ter probabilidade de que sofra alteração, a despeito de novos tratamentos (deficiência permanente), além da perda ou anormalidade que tende a uma redução efetiva e acentuada da capacidade de integração social, demandando a necessidade de equipamentos, adaptações, meios ou recursos especiais para que a pessoa portadora de deficiência possa receber ou transmitir informações necessárias ao seu bem-estar pessoal e ao desempenho de uma função ou atividade (incapacidade) (BISPO, 2008, s/n).

Aos aspectos limitantes da deficiência, que alcançam relevância através do diagnóstico conclusivo da área médica, se impõe as possibilidades de desenvolvimento, as formas de superação das dificuldades, cabendo à família um papel fundamental no processo de intermediação e integração dos seus portadores diante da comunidade, demandando tal situação uma inter-relação envolvendo desde os grupos de apoio até os centros de educação e terapia, à medida que o comportamento dos portadores de necessidades especiais suscita diferentes formas de preconceitos, inquietações e reações, tendo em vista o estigma que emerge da concepção da sociedade que atribui à condição 
em questão o caráter de um peso ou um problema, transformando-os em seres incapazes no tocante à adaptação que acena com a convivência social, tanto quanto - e principalmente - no que concerne ao exercício de uma atividade profissional, relegandoos, enfim, às fronteiras sociopolíticas das práticas assistencialistas que geralmente caracterizam as relações entre o poder e as minorias.

\title{
Da Diversidade e a "Dialética da Afirmação"
}

\begin{abstract}
O principio da continuidade e da regularidade que o objetivismo concede ao mundo social sem poder explicá-lo é o sistema de disposições passado que sobrevive no atual e que tende

a perpetuar-se no futuro, atualizando-se nas práticas estruturadas segundo seus princípios - lei interior através da qual se exerce continuamente a lei das necessidades externas irredutíveis às pressões imediatas da conjuntura. Ao mesmo tempo, o sistema de disposições é o princípio das transformações e das revoluções regradas que nem os determinismos extrínsecos e instantâneos de urn sociologismo mecanicista, nem a determinação puramente interior mas puramente pontual do subjetivismo voluntarista ou espontaneísta conseguem explicar. (BOURDIEU, 1983, p. 76)
\end{abstract}

Servindo de álibi à preponderância, a diversidade perfaz, em certo sentido, uma espécie de honra conferida pelo dominador aos povos dominados, que através da referida homenagem tendiam a manter, sob a perspectiva da originalidade, a sua condição, constituindo-se um instrumento capaz de dissimular o desequilíbrio da relação ora instaurada, carregando também a acepção que alcança relevância nesta investigação e a caracteriza, em suma, como a proclamação do direito à diferença, que converge para a afirmação dos seres e das coisas, das classes e dos povos, das culturas, em última instância, diante da uniformidade que se impõe ao mundo, se lhe contrapondo, perfazendo, enfim, "uma forma de resistência contra a falsa História" (DUVIGNAUD, 1971, p. 128).

A distinção de uma espécie das outras espécies do mesmo gênero, eis a característica da diversidade, que emerge do âmbito da lógica naturalista e perfaz uma definição que acena com a leitura aristotélica, esgotando-se como tal à medida que não guarda possibilidade de corresponder a todas as implicações que o referido fenômeno carrega, tendo em vista a concepção de que "o homem é menos um ser de lógica e de natureza que de História", convergindo a vivência e a instauração daquilo que encerra relações sinonímicas com divergência, contradição e oposição, e que remete à acepção que envolve pluralidade, multiplicidade, heterogeneidade e variedade, nas fronteiras de grupos e comportamentos, para uma "eflorescência em leque", que supõe uma 
alternância de desdobramentos e fechamentos que o homo sapiens sobrepõe à diversificação natural dos gêneros em espécies, tornando-se relevante o fato de que se os "jogos" para estas "estão feitos", para aquele, que incessantemente se faz e se joga, jamais os tais alcançam a referida condição, cuja perspectiva acena com a ambiguidade no tocante a sua noção corolário, a saber, a especificidade, que demanda uma dialética que produza a sua inserção na generalidade do mundo e no projeto do homem (DUVIGNAUD, 1971, p. 129).

Nesta perspectiva, pois, alcança relevância o status filosófico conferido à diferença pela leitura deleuziana ${ }^{4}$, que, à medida que a sua inserção se impõe à dialética da identidade, se lhe imputa a condição de um falso problema, convergindo para uma noção que a caracteriza como fundamento de toda realidade ${ }^{5}$, não circunscrevendo-a ao âmbito de uma simples fraude ou compromisso do idêntico, interpretação que, em virtude do quadro histórico que a encerra, não deixa de perfazer um horizonte de interesse do campo sociológico, tendo em vista a série de impasses que acarreta o processo em questão, pois se a redutibilidade, no que tange às minorias étnicas, culturais ou políticas, implica uma pressuposição da visão individual, tornando-se necessário um simples esforço em direção às fronteiras da verdade para possibilitar a superação dos riscos envolvendo estereótipos, preconceitos e animosidades que se correlacionam na construção da intolerância e do racismo ${ }^{6}$, o que, no entanto, não guarda capacidade de eliminar absolutamente a discriminação, principalmente nos casos que assinalam um fenômeno que, desde sempre mantendo interdependência, menos do que da subjetividade do interlocutor (sujeito ou indivíduo que participa da interação social e consciente ou inconscientemente exerce a conduta coercitiva que a homogeneização cultural rege) emerge da esfera do próprio "minoritário", acenando com uma licença, uma permissão, uma autorização que, em virtude da interiorização da referida disposição - ou melhor, em face da "interiorização da exterioridade"7, segundo Bourdieu -, tende a assumir inevitáveis contornos objetivos nas configurações

4 . DELEUZE, 2006.

5 . "É essa noção de diferença que lhe permitirá conceber a vida e o mundo como processos de criação do novo, como constituídos de processos intensivos (forças, fluxos, movimentos, em relação entre si), mais do que de unidades extensivas (elementos distintos distribuídos no espaço)" (TADEU, s/d, p. 9).

6 . “(...) é preciso ter em mente que não há um racismo, mas vários racismos: há tantos racismos quantos grupos que precisem justificar a sua existência como tal, o que constitui a função invariante dos racismos" (BOURDIEU, 1983, p. 205).

7 . "Na natureza humana, 'existe interiorização da exterioridade e exteriorização da interioridade': as condições sociais objectivas (sic) de existência são interiorizadas pelos indivíduos na forma de habitus (do latim 'maneira de ser')" (BARAQUIN; LAFFITTE, 2004, p. 78, grifo do autor). 
intersubjetivas.

Pelo fato de que a identidade das condições de existência tende a produzir sistemas de disposições semelhantes (pelo menos parcialmente), a homogeneidade (relativa) dos habitus que delas resulta está no principio de uma harmonização objetiva das práticas e das obras, harmonização esta própria a lhes conferir a regularidade e a objetividade que definem sua "racionalidade" especifica e que as fazem ser vividas como evidentes ou necessárias, isto é, como imediatamente inteligíveis e previsíveis, por todos os agentes dotados do domínio prático do sistema de esquemas de ação e de interpretação objetivamente implicados na sua efetivação e por esses somente (quer dizer, por todos os membros do mesmo grupo ou da mesma classe, produtos de condições objetivas idênticas que estão destinadas a exercer simultaneamente um efeito de universalização e de particularização, na medida em que elas só homogeneizam os membros de um grupo distinguindo-os de todos os outros). (BOURDIEU, 1983, p. 66-67, grifos do autor)

Se o que se impõe, diante da impossibilidade de uma integração imediata dos portadores de deficiência, transtornos globais do desenvolvimento (TGD) e altas habilidades ou superdotação, ou melhor, em face da instauração e funcionamento de um sistema educacional inclusivo que corresponda aos parâmetros legislativos, tanto quanto, antes, às necessidades daqueles no âmbito do processo formativo-educacional, é a afirmação do direito à diferença, que se sobrepõe ao papel da antítese, não se circunscrevendo ao âmbito da alteração propriamente, à medida que deve, em função da necessidade de se expandir, superar a resistência, convergindo para uma pluralidade que possibilite a emergência de identidades empíricas cuja disposição, no arcabouço social, não se caracterize senão através de uma percepção imediata que não se detenha no viés da visão oblíqua que carrega a racionalidade instrumental e a objetividade reducionista, se lhes escapando, mas que, guardando raízes no nicho de uma noção ambígua (que se contrapõe a acepção de unidade, que tem a mesma condição), seja capaz de conviver com a tensão realista que remete ambas aos extremos na esfera das manifestações coletivas, as quais, trazendo uma dinâmica fundada sobre movimentos complexos, que na zona de intersecção que abrange "Coletividades" e "Indivíduos" reúnem elementos que ora se cristalizam ora se diluem, passíveis de ênfases distintas, constituindo-se o fenômeno do exercício do direito em questão não menos do que uma construção. "A exaltação do diverso redunda na colocação em ação de riquezas inerentes ao psiquismo humano e à vida do grupo" (DUVIGNAUD, 1971, p. 139).

\section{Da Educação Inclusiva e os aspectos organizativos, curriculares e profissionais}


O processo formativo-educacional, na relação que implica a participação do público infanto-juvenil portador de necessidades educacionais especiais (NEE), converge, no território brasileiro, no período que envolve a primeira década do séc. XXI, para a necessidade de adequabilidade, ajustabilidade e adaptabilidade no que tange à inclusão do referido contingente, perfazendo uma conjuntura que traz o arcabouço legislacional, ou antes, a reivindicação do cumprimento das suas normas e regras, como fator determinante da disposição de identificação solidária (solidarização) das estruturas socioculturais em face da integração que se lhe impõe a condição de cidadania ${ }^{8}$ que pelo menos teoricamente não detém nenhuma exceção dentre aqueles que pertencem à determinada comunidade que desde sempre se caracteriza como sociopolítica - porque constitutivos da mesma -, conforme sintomatiza a inexistência de infraestrutura logística, financeira e profissional, que, circunscrevendo, em certo sentido, o processo às fronteiras que pressupõem que a dimensão social esgota-se através da contiguidade, não emerge senão através da incapacidade da instituição escolar de possibilitar sequer o acesso às suas dependências aos educandos com deficiência ou transtorno global do desenvolvimento (TGD), além da insuficiência de recursos que permitam a disponibilização de materiais que a dinâmica do fenômeno de ensino-aprendizagem destes demanda e da inoperância das técnicas procedimentais e comportamentais dos educadores na sua instauração, que exige uma conjugação que abrange da ineficiência do paradigma curricular à impropriedade da didática, em suma, alcançando relevância as experiências desenvolvidas aleatoriamente, as quais, pretendendo transpor o abismo das coordenadas que encerram teoria e prática, assinalam o tipo de esforço que o êxito de tal empreendimento, enfim, requer.

A experiência de Roberta Martins Braz Villaça, da EMEB Helena Zanfelici da Silva, em São Bernardo do Campo, na região metropolitana de São Paulo, comprova isso. Entre seus 24 alunos da pré-escola está Isabelly Victoria Borges dos Santos, 5 anos, que tem paralisia cerebral. Apesar do comprometimento motor, a menina tem a capacidade cognitiva preservada. $\mathrm{Na}$ escola desde o ano passado (2010), ela participa de todas as atividades. "Os conteúdos trabalhados em sala são os mesmos para ela. O que eu mudo

\footnotetext{
8. A definição de cidadania que se impõe à sociedade contemporânea, com as devidas reservas críticas que uma concepção liberal demanda, emerge do ensaio clássico de T. H. Marshall intitulado "Cidadania e classe social", publicado em 1949, que afirma: "A cidadania é um status concedido àqueles que são membros integrais de uma comunidade. Todos aqueles que possuem o status são iguais com respeito aos direitos e obrigações pertinentes ao status. Não há nenhum princípio universal que determine o que estes direitos e obrigações serão, mas a sociedade nas quais a cidadania é uma instituição em desenvolvimento criam uma imagem de uma cidadania ideal em relação à qual o sucesso pode ser medido e em relação à qual a aspiração pode ser dirigida" (MARSHALL, 1967, p. 76 , grifos do autor).
} 
são as estratégias e os recursos", explica a professora. (BIBIANO, 2011, p. 49)

Nesta perspectiva, se a distinção envolvendo os conteúdos programáticos carrega a possibilidade de se tornar contraproducente, à medida que tende a produzir discrepâncias na construção do resultado do processo formativo-educacional, que se mantém na contemporaneidade sob a égide da lógica do mercado de trabalho, privilegiando a racionalidade instrumental e o saber tecnocientífico em detrimento do horizonte humanístico, a mudança das estratégias e a interposição de recursos apropriados no que tange à situação de ensino-aprendizagem ora instaurada diante de um portador de deficiência ou transtorno global de desenvolvimento (TGD) se caracterizam como imprescindíveis para a superação da inadequação que as diferenças em questão engendram, convertendo-as, através da socialização que a sua participação implica, em possibilidades, desde que a inclusão, termo cuja utilização acena com o paradoxo que a pressuposição da sua antonímia acarreta, seja não menos do que um projeto da instituição educacional, convergindo para uma ação que além do exercício das práticas pedagógicas que se impõem geralmente ao processo formativo-educacional, que inter-relacionam do planejamento (plano de trabalho) à avaliação, da contextualização aos objetivos, conteúdos e metodologia, da práxis entre o ideal político-pedagógico e a realidade sócio-histórica à multidisciplinaridade ${ }^{9}$, à interdisciplinaridade $^{10}$, à transdisciplinaridade ${ }^{11}$, da sequência didática aos temas transversais, entre outras, demanda a intervenção de uma equipe que reúna desde uma auxiliar de serviços referentes à alimentação e higiene pessoal até a profissional do atendimento educacional especializado (AEE), tornando-se fundamental para o êxito do investimento o comprometimento da família do portador de deficiência ou transtorno global de desenvolvimento (TGD).

Em decorrência da ausência de política de formação de professores para o

9. "A multidisciplinaridade acontece quando um tema é abordado por diversas disciplinas sem uma relação direta entre elas. Se o objeto de estudo for o Cristo Redentor, por exemplo, a Geografia trabalhará a localização; as Ciências tratarão da vegetação local; as Artes mostrarão por quem a escultura foi feita e por que está ali. Mas as abordagens são específicas de cada disciplina e não há interligação" (CAVALCANTE, 2004, p. 55).

10 . "Na interdisciplinaridade, duas ou mais disciplinas relacionam seus conteúdos para aprofundar o conhecimento. Dessa forma, o professor de Geografia, ao falar da localização do Cristo, poderia utilizar um texto poético, assim como o de Ciências analisaria a história da ocupação da cidade para entender os impactos ambientais no entorno" (CAVALCANTE, 2004, p. 55).

11. "A transdisciplinaridade é uma abordagem mais complexa, em que a divisão por disciplinas, hoje implantada nas escolas, deixa de existir. Essa prática somente será viável quando não houver mais a fragmentação do conhecimento" (CAVALCANTE, 2004, p. 55). 
atendimento educacional especializado, observa-se que a oferta desse serviço na rede pública tem diminuído consideravelmente a partir do final da década de 90. Algumas universidades extinguiram cursos de habilitações específicas. $\mathrm{Na}$ falta de professores especializados, os serviços públicos e as escolas especiais para deficientes mentais e instituições especializadas na área da deficiência visual, auditiva, física e outras tiveram que recorrer a cursos de extensão ou treinamento em serviço. Assim, abre-se uma lacuna no ensino superior e torna-se evidente a exigência de reformas educativas, de projetos, de cursos de Pedagogia, tendo em vista a formação de professores para o atendimento educacional especializado e para a inclusão de pessoas com deficiência no ensino regular. (BRUNO, 2007, s/n)

Se em função da diversidade o processo de inclusão guarda possibilidade de escapar à construção de princípios básicos, a formação do corpo docente se impõe como uma medida capaz de assegurar as condições mínimas quanto à funcionalidade do sistema em questão, à medida que o seu papel se sobrepõe à ausência de um espaço físico adaptado, o qual, embora indispensável, não se torna suficiente diante da incapacidade do professor no tocante à administração dos recursos porventura disponíveis, alcançando relevância a revisão dos referenciais teórico-metodológicos que, destinados a um público que não abrange os indivíduos portadores de necessidades especiais, não correspondem a estes, cujos objetivos, envolvendo o ensino, equivalem àqueles que caracterizam qualquer cidadão, tornando-se imprescindível a redefinição dos currículos escolares e a mudança tanto das concepções epistemológicas como das práticas avaliativas, dos pressupostos didático-pedagógicos da aprendizagem, enfim.

\begin{abstract}
A educação das necessidades educacionais especiais, no contexto do ensino regular, permite, tanto aos professores já atuantes quanto aos que estão em formação, rever os referenciais teórico-metodológicos que se alicerçaram na distinção entre educação especial

e geral, uma vez que (...) a educação dos alunos com necessidades especiais tem os mesmos objetivos da educação de qualquer cidadão. (...) Incluir e garantir uma educação de qualidade para todos é, hoje, o fator mais importante na redefinição dos currículos escolares, desafiando a coragem das escolas em assumir um sistema educacional 'especial' para todos os alunos. (FREITAS, 2006, p. 166)
\end{abstract}

Se a práxis educativa, em função da sua natureza, escapa à neutralidade, no âmbito da sociedade contemporânea ("sociedade da informação"), impõe-se à instituição escolar, como arcabouço do conhecimento, o papel de centro organizacional dos múltiplos espaços de formação, que cumpra uma função mais formativa e menos informativa (GADOTTI, 2007, p. 6), à medida que, carregando um corpo sistemático de representações que determina as fronteiras do pensamento, normatizando a conduta e condicionando o comportamento, pois, converge para adaptar aos espaços 
preestabelecidos pela sociedade os indivíduos, assegurando a estruturalidade da relação destes entre si e com suas condições de existência, acenando com a possibilidade de manter o complexo social sob a perspectiva da unidade e harmonia.

Nesta perspectiva, pois, eis a condição da educação especial:

(...) é parte da educação básica e geral, e a escola tem por uma de suas responsabilidades organizar-se de forma que permita aos educandos a aprendizagem de conteúdos específicos de cada nível educativo. Nessa compreensão, as necessidades educacionais especiais referem-se à presença de dificuldades para aprender alguns conteúdos do currículo básico. Paradoxalmente, espera-se que o sistema escolar se adeqüe às necessidades dos alunos. (DENARI, 2006, p. 36-37)

À diversidade se impõe uma resposta da instituição escolar que envolva a estruturalidade organizativa, curricular e profissional e mobilize todos os integrantes do processo, se o que se impõe é a superação de um modelo que acena com a redução do outro, a visão unilateral e a falta de percepção da complexidade humana, fatores que inter-relacionados caracterizam desde a elaboração da grade curricular e a burocratização das atividades até os métodos e tecnologias de ensino que remetem a uma concepção reprodutivista no tocante à aquisição do conhecimento, que converge para a emergência de uma racionalidade que mantém em nichos incomunicáveis teoria e prática, aluno e saber, educador e educando, tendo em vista que a perspectivação em questão guarda correspondência, no tocante ao planejamento escolar, com o horizonte que protege o âmbito da sua definição, sob o qual acontece a inter-relação de ideias, valores e práticas que emergem de uma concepção de existência que escapa ao "real", conhecendo apenas o "objetivo", pressuposto científico com o qual o pedagogismo contemporâneo ainda dialoga, fragmentalizando sujeito e realidade, mundo subjetivo e mundo objetivo, possibilidade circunscrita ao âmbito teórico que não encontra, pois, eco na prática vivencial, cuja experiencialização, implicando a autoafirmação humana (para cujas fronteiras acena a educação), envolve a gestação de liames de intersubjetividade, de raízes interindividuais que convergem para a estruturalização do emaranhado do eu, abrangendo da percepção de conceitos (inteligência) à sensibilidade aos valores morais (consciência ética), da sensibilidade aos valores estéticos (consciência estética) à sensibilidade aos valores sociopolíticos (consciência política).

\section{Sociedade Igualitária e Sistema Educacional Inclusivo (Teoria e Prática)}


O desafio que confronta a escola inclusiva é no que diz respeito ao desenvolvimento de uma pedagogia centrada na criança e capaz de bem sucedidamente educar todas as crianças, incluindo aquelas que possuam desvantagens severas. O mérito de tais escolas não reside somente no fato de que elas sejam capazes de prover uma educação de alta qualidade a todas as crianças: o estabelecimento de tais escolas é um passo crucial no sentido de modificar atitudes discriminatórias, de criar comunidades acolhedoras e de desenvolver uma sociedade inclusiva. (DECLARAÇÃO DE SALAMANCA, 1994, p.4)

Se a "igualdade de condições para o acesso e permanência na escola" (BRASIL/MEC, $1988^{12}$ ) é um dos princípios da base do exercício do ensino, a "democratização" do sistema educacional, no tocante às categorias antes excluídas (independentemente dos fatores envolvidos, desde o socioeconômico ao sociocultural), encerra um caráter paradoxal, à medida que embora possibilite o "direito" ao acesso à escola $^{13}$, mantém as prerrogativas decorrentes do privilégio "cultural" dos mais favorecidos, como exemplifica o caso envolvendo os portadores de deficiência, transtornos globais do desenvolvimento (TGD) e altas habilidades ou superdotação, tendo em vista que à estrutura da legislação se impõe a construção dos meios necessários para a viabilização do seu integral cumprimento e consequente usufruto através daqueles em função dos quais teoricamente existe, tornando-se relevante, nesta perspectiva, o horizonte para o qual convergem os marcos político-legais da Educação Especial, segundo o exposto no Decreto No 6.571 , de 17 de Setembro de $2008^{14}$.

\footnotetext{
Art. 1o A União prestará apoio técnico e financeiro aos sistemas públicos de ensino dos Estados, do Distrito Federal e dos Municípios, na forma deste Decreto, com a finalidade de ampliar a oferta do atendimento educacional especializado aos alunos com deficiência, transtornos globais do desenvolvimento e altas habilidades ou superdotação, matriculados na rede pública de ensino regular.

$\S 1^{\circ}$ Considera-se atendimento educacional especializado o conjunto de atividades, recursos de acessibilidade e pedagógicos organizados institucionalmente, prestado de forma complementar ou suplementar à formação dos alunos no ensino regular.

$\S 20 \mathrm{O}$ atendimento educacional especializado deve integrar a proposta pedagógica da escola, envolver a participação da família e ser realizado em
}

12 . Parágrafo I, Artigo 206, Seção I (Da Educação), Capítulo III (Da Educação, Da Cultura e Do Desporto), do Título VIII (Da Ordem Social).

13 . "Não é suficiente oferecer-se escolas para todos, é essencial que o 'todos' não perca a dimensão da individualidade, e que, uma vez na escola, esta ofereça a cada criança e jovem a oportunidade máxima possível de alcançar sua cidadania plena pelo respeito e pela aprendizagem" (HOFFMANN, 2004, p. 36).

14 . Dispõe sobre o atendimento educacional especializado, regulamenta o parágrafo único do art. 60 da Lei $\mathrm{n}^{\circ}$ 9.394, de 20 de dezembro de 1996, e acrescenta dispositivo ao Decreto $\mathrm{n}^{\circ} 6.253$, de 13 de novembro de 2007. 
articulação com as demais políticas públicas.

Art. 2o São objetivos do atendimento educacional especializado:

I - prover condições de acesso, participação e aprendizagem no ensino regular aos alunos referidos no art. $1^{\mathrm{o}}$;

II - garantir a transversalidade das ações da educação especial no ensino regular;

III - fomentar o desenvolvimento de recursos didáticos e pedagógicos que eliminem as barreiras no processo de ensino e aprendizagem; e

IV - assegurar condições para a continuidade de estudos nos demais níveis de ensino. (BRASIL/MEC/SEESP, 2008)

Se não há consenso no Brasil no tocante à inclusão de crianças com necessidades especiais em escolas regulares, não escapa também à polêmica países como o Reino Unido, cujo governo se envolveu na discussão do referido tema com os educadores na década de 1990, ocasião que mostra a decisão das cidades no sentido de extinguir as instituição de educação especial e encaminhar os que a frequentavam para àquelas, juntando todos os educandos, situação que, no entanto, não perdurou em muitas delas, tendo em vista que mudaram de ideia, preferindo manter estabelecimentos de ensino regular vizinhos aos que proporcionam atendimento especializado, ficando relegada a interação dos alunos a um horário específico, programado $\left(\mathrm{CAFARDO}^{1}\right.$, 2008, A21).

A justificativa para o procedimento em questão guarda relação com o caráter econômico, à medida que a inclusão demanda um investimento que envolve materiais, instrumentos e professores com formação específica, a viabilidade do qual não alcança a totalidade do sistema educacional senão aquelas instituições especializadas que, no Reino Unido, prestam atendimentos a estudantes que trazem deficiências graves ou geradoras de um alto comprometimento do desenvolvimento, como as que têm paralisia cerebral, doenças neurodegenerativas, síndrome de Down, permanecendo os portadores de distúrbios mentais como transtorno do déficit de atenção ou dislexia no âmbito dos estabelecimentos de ensino regular (CAFARDO' ${ }^{1}, 2008$, A21).

Submetida à assistência de fonoaudiólogos e psicólogos, antes de receber autorização para cursar uma instituição de educação especial, a criança atravessa determinadas etapas no estabelecimento de ensino regular que objetivam viabilizar o progresso da sua aprendizagem que, uma vez não concretizada, possibilita, através de um processo de avaliação de uma equipe especializada, o seu encaminhamento para a escola especial, tornando-se relevante a constatação quanto à adaptação de certo número de alunos especiais às condições das escolas regulares daquele país. "Educação e tratamento de saúde são pagos pelo governo. Pouco mais de 220 mil - do total de 7,9 
milhões de alunos ingleses - são oficialmente estudantes com necessidades especiais. Quase 40\% estão em escolas especiais" (CAFARDO ${ }^{1}, 2008$, A21).

“(...) O importante é fazer o melhor para elas", eis as palavras de Chrissy Hector, assistente da direção da Bridge School (norte de Londres), instituição de educação especial que presta atendimento a 75 crianças de 5 a 11 anos e a outros 75 adolescentes, em dois prédios diferentes, nos quais os alunos são separados não em função das suas deficiências mas por suas habilidades, à medida que contam com seguinte estrutura:

\begin{abstract}
As salas de aula são identificadas por cores. E todas têm instrumentos musicais e monitores de LCD em que são projetados softwares especiais. Há piscinas e até cozinhas adaptadas para que os meninos e meninas aprendam a cozinhar, lidar com dinheiro e viver com independência fora dali. $\left(\mathrm{CAFARDO}^{1}, 2008, \mathrm{~A} 21\right)$
\end{abstract}

Se a proporção envolvendo o número de alunos e de professores ou assistentes não é senão de menos de 2 para 1, aos educadores ingleses que atuam em instituições como a Bridge é atribuído um salário maior do que àqueles que trabalham em estabelecimentos de ensino regular, correspondendo inicialmente o seu valor a aproximadamente $£ 2$ mil ( $\mathrm{R} \$ 6,8$ mil), mensalmente, havendo possibilidade de alcançar o patamar de $£ 4$ mil ( $\mathrm{R} \$ 13,6$ mil) posteriormente, tornando-se relevante o fato envolvendo o investimento das empresas do Reino Unido na produção de tecnologia e materiais para crianças com necessidades especiais que envolvem desde equipamentos sofisticados (monitores que trazem funções que podem ser acionadas pelo toque na tela, por exemplo) até simples brinquedos que estimulam os sentidos ou rodelas de borracha que facilitam o uso do lápis por crianças com dificuldades de coordenação motora $\left(\right.$ CAFARDO $^{1}, 2008$, A21).

Se o exemplo em questão acena com a possibilidade de propor um horizonte de discussão acerca da tensão que se impõe à inter-relação que, no que concerne à educação inclusiva, envolve teoria e prática, demonstrando não a sobreposição do "real" em face do "ideal" mas um diálogo que não deixa de convergir para uma síntese transformadora, jamais definitiva, o que se impõe ao contexto brasileiro, como resultado do esforço empreendido no sentido de corresponder ao desafio proposto pela Declaração de Salamanca, é a constatação de um aumento que ultrapassa 500\% (de 43 mil para 306 mil) nos últimos dez anos, em relação ao número de alunos portadores de deficiências que estudam em instituições de ensino regular, assumindo o MEC a defesa da sua 
integração com outras crianças, à medida que tal processo possibilita tanto $\mathrm{o}$ desenvolvimento dos educandos especiais como a emergência da diversidade nos estabelecimentos de ensino, tendo se elevado de 6 mil para 62 mil o número de escolas regulares que atendem a este público, a despeito da maioria das crianças e jovens com deficiência (348,4 mil) permanecer vinculada às escolas especiais (CAFARDO², 2008, A21).

\section{Da Educação Inclusiva: Das Diferenças como Possibilidades}

(...) experimentamos a transição de um novo modo de ser. Essa nova ordenação característica de nossa atualidade se apresenta como uma forte crise de concepções, decerto decorrente da coexistência de velhos e novos valores. Como toda transição, a convivência do velho com o novo, ao mesmo tempo em que exige mudança, gera insegurança naqueles que se vêem diante da necessidade de substituir o conhecido e o seguro pelo desconhecido. Por conseguinte, concepções são postas em xeque, e novas formas de encarar o mundo preenchem os espaços deixados pela derrocada das antigas idéias. (...) O desafio está lançado. Não há receitas prontas, por isso não há caminho a trilhar, mas a abrir. $\mathrm{O}$ único instrumento que temos hoje para iniciar essa caminhada é a certeza de que é preciso romper definitivamente com a idéia do absoluto, do padrão homogeneizante de condutas e de corpos. Assumir a diversidade é, em suma, assumir a vida como ela é: rica e bela na sua forma plural. (MARQUES; MARQUES, 2003, p. 229; 238)

Se ao sistema educacional se impõe uma resposta à diversidade que envolva a reestruturalização organizativa, curricular e profissional, cuja reorganização acena com um horizonte que abrange desde a especialização magisterial, ou pelo menos a introdução dos seus pressupostos na formação do corpo docente, até a adaptação da prática pedagógica, além do incremento do espaço físico, considerando a necessidade quanto a instalação de zonas de recursos multifuncionais que possibilitem a participação do educando especial no processo de ensino-aprendizagem, a incapacidade de atender aos portadores de necessidades especiais, que demanda um estímulo suplementar, inclusive o acompanhamento de equipe multidisciplinar (fonoaudiólogos, assistentes sociais, psicólogos, terapeutas ocupacionais), converge para impossibilitar o acesso ao mercado de trabalho, a despeito da legislação instituir a obrigatoriedade de reserva de postos em empresas privadas à portadores de deficiência segundo os percentuais abaixo listados, de acordo com o art. 93 da Lei 8.213 de 24 de julho de 1991 (Plano de Benefícios de Previdência Social):

A empresa com 100 (cem) ou mais empregados está obrigada a preencher de $2 \%$ (dois por cento) a $5 \%$ (cinco por cento) dos seus cargos com beneficiários reabilitados ou pessoas portadoras de deficiência, habilitadas, na seguinte 
proporção:

I - até 200 empregados - 2\%; II - de 201 a 500 empregados - 3\%; III - de 501

a 1000 empregados - 4\%; IV - de 1001 em diante - 5\% (BRASIL/MPAS, 1991)

À reestruturação das instituições, que não se esgotando através de um horizonte meramente técnico converge para a conscientização da sociedade através de mudanças de atitude, compromisso e disposição, não envolve apenas a área educacional mas alcança também os setores da saúde, lazer, esportes, cultura e transportes, tanto quanto do próprio mercado de trabalho, à medida que o recrutamento de uma força profissional diversificada transpõe as fronteiras da responsabilidade social, tornando-se uma questão de necessidade, acenando com a equiparação de oportunidades, a mútua interação de indivíduos portadores ou não de necessidades especiais e o pleno acesso aos recursos da sociedade, caracterizando uma preocupação e um interesse que demonstram o papel e o valor atribuídos às minorias em um determinado contexto sócio-político, configurando, enfim, uma medida de ordem econômica, uma vez que detém a capacidade de engendrar cidadãos produtivos, participantes, conscientes de seus direitos e deveres, em suma, possibilitando, dessa maneira, a redução dos custos sociais (MACIEL, 2000, s/n).

\begin{abstract}
Além da dignidade humana, outros princípios constitucionais se alinham para permitir maior proteção ao portador de necessidades especiais em várias facetas da vida.

O princípio da não-discriminação do trabalhador decorre, dentre outros, dos princípios da igualdade e da isonomia, não cabendo aqui a conceituação de cada princípio mas, sobretudo, sua contextualização no objeto deste trabalho: tais princípios contribuem para o equilíbrio de forças entre os chamados direitos individuais e os direitos sociais.

É nesse sentido a importância de tais princípios para a questão do trabalhador especial: sua observância determina a compatibilização entre as liberdades ditadas pela livre iniciativa e o necessário valor social do trabalho, considerando-se o indivíduo especial em todas as suas potencialidades, retirando-o do papel de coadjuvante de sua própria existência e conferindolhe papel decisivo na construção da sonhada sociedade livre, justa e solidária preconizada pela constituição da república. (BISPO, 2008, s/n)
\end{abstract}

Se o portador de deficiência e de necessidades especiais detém em caráter temporário ou permanente, significativas diferenças físicas, sensoriais ou intelectuais, que guardam relação com fatores inatos ou adquiridos, que acarretam dificuldades em sua interação com o ambiente social, tornando-se imprescindível, por essa razão, a utilização de recursos especializados que viabilizem o desenvolvimento do seu potencial e a superação ou a minimização da sua situação crítica, a sua inserção no 
mercado de trabalho se impõe como um mecanismo que acena com as condições de sobrevivência e realização psicológica, à medida que os indivíduos em questão possuem aptidões inatas e capacidades adquiridas, as quais, condicionadas embora a uma deficiência (ou seja, a falta de um determinado potencial físico ou sensorial), emergem da estrutura da sua personalidade, gerando reações e manifestações que não carregam senão a pretensão de promover a adaptabilidade à situação referida, o que efetivamente acontece quando os interlocutores tendem a vislumbrar as diferenças como possibilidades (diferenciais), se é verdadeira a pressuposição de que a redução da capacidade destes (os portadores de deficiência e de necessidades especiais), em certo sentido, não independe totalmente das limitações deflagradas pelo arcabouço sociocultural.

O treinamento e o aprimoramento do potencial dos portadores de deficiência e de necessidades especiais, tanto quanto o reconhecimento e a identificação dos bloqueios que carregam, eis o que se impõe ao processo de inclusão social, desde a formação educacional até o ingresso no mercado de trabalho, à medida que o processo de inserção destes no campo profissional demanda iniciativas que implicam desde o exercício de uma supervisão especial no âmbito de um ambiente de trabalho normal que, no caso, tenha um grupo que os reúna, conforme assinala o funcionamento dos "enclaves", até a possibilidade da instauração de uma atividade laboral sob condições normais, diante daqueles que detenham ou não deficiência ou necessidades especiais, perfazendo uma condição que, requerendo o apoio de especialistas, visa, através do fenômeno da socialização no exercício profissional, não menos do que a integração, propriamente dita.

À questão que envolve a vida profissional se impõe a responsabilidade do Estado que não se esgotando através da criação de oportunidades de colocação demanda antes a formação profisssional, além do incentivo em relação às práticas de reabilitação, tendo em vista a necessidade quanto à conservação do posto de trabalho e à ascensão profissional, à medida que uma prática inclusiva acena com a reafirmação da mitigação das desigualdades no ambiente laboral, seja no que concerne à inserção dos trabalhadores no mercado (independentemente das suas diferenças), seja no tocante às condições do exercício laboral, conforme a proposta da Organização Internacional do Trabalho (OIT), que, através do Programa de Promoção dos Direitos e Oportunidades de Emprego das Pessoas Portadoras de Deficiência, objetiva buscar, sobretudo através 
de ações de qualificação, apoio e conscientização, soluções para os desafios enfrentados pelo profissional portador de deficiência (BISPO, 2008, s/n).

À situação do trabalhador portador de necessidades especiais se impõe uma iniciativa política que mais do que um resultado que represente uma luta isolada de grupos que reivindicam o reconhecimento de direitos se constitua um fenômeno que traz como eixo a diversidade, incluindo em seu arcabouço as especificidades em questão, desde a esfera educacional até o âmbito trabalhista (no sentido de preparar ambas para cumprir a sua função social), de cuja inter-relação emerge a própria cidadania, que, seja qual for o sentido que carrega, implica uma dinâmica que não converge senão, no âmbito da contemporaneidade, para as fronteiras que encerram em contrapartida utilidade e produtividade, que emergem como ângulos que estruturalizam o funcionamento das instituições que se caracterizam, pois, como um conjunto de princípios, regras, métodos e procedimentos minuciosos, graduais, calculados, que pretende assegurar o equilíbrio da sociedade desde a modernidade, acenando com uma organizacionalidade inclinada à visão "cientificista" de progresso que demanda, antes da classificação das partes que a integram, tanto quanto da seleção, enfim, dos seus membros, os indivíduos, uma ação capaz de torná-los aptos (ou não) ao sistema, pressuposto do processo formativo-educacional, segundo a perspectiva que realística e criticamente assinala que "não se trata, pois, da iniciação num mundo comum que transcende nossa existência individual, mas do treinamento necessário ao labor da vida social (CARVALHO, s/d, p. 23, grifos do autor).

\footnotetext{
Com um capítulo específico para a Educação Especial, a Lei 9.394/96 exige dos sistemas de ensino uma educação especial para o trabalho, viabilizando a inserção dos educandos especiais nas diversas possibilidades de trabalho (art. 59 , IV), com preferência para a oferta na rede regular de ensino.

Também a Resolução CNE/CEB (13) $n^{\circ}$ 02, de 11 de setembro de 2001, possui disposições específicas quanto à preparação do ambiente de formação dos educandos especiais, denotando preocupação específica com o desenvolvimento de suas potencialidades (arts. $3^{\circ}, 4^{\circ}, 16$ e 17). (BISPO, $2008, \mathrm{~s} / \mathrm{n})$
}

De acordo com tal leitura, emerge, pois, como um dos principais problemas do processo formativo-educacional a questão que envolve a sua incapacidade de cumprir as pretensões conjugadas no âmbito da sua construção identitária, principalmente no que concerne ao indivíduo portador de necessidades especiais, cujo treinamento e aprimoramento do potencial, tanto quanto o reconhecimento e a identificação dos bloqueios que carregam, se impõem como um processo que envolve a reestruturação 
das instituições, que não se esgotando através de um horizonte meramente técnico converge para a conscientização da sociedade através de mudanças de atitude, compromisso e disposição, que não envolve apenas a área educacional mas alcança também os setores da saúde, lazer, esportes, cultura e transportes, tanto quanto do próprio mercado de trabalho, à medida que o recrutamento de uma força profissional diversificada transpõe as fronteiras da responsabilidade social, tornando-se uma questão de necessidade, acenando com a equiparação de oportunidades, a mútua interação de indivíduos portadores ou não de necessidades especiais e o pleno acesso aos recursos da sociedade.

\section{Aspectos Conclusivos}

À diversidade se impõe uma perspectiva que implica desde o modo pelo qual a sua manifestação se dispõe aos sentidos até a sua emergência na análise, envolvendo tanto a resistência que carrega no que tange às reduções como a sua participação na disputa de um mundo que não se caracteriza senão como uma construção que guarda possibilidade de se refazer, detendo uma necessidade que demanda, na leitura do caso em questão, a superação das intimações do falso unitarismo e das acusações ou insinuações que lhe são atribuídas, à medida que converge para a ambigüidade, que em suas fronteiras encerra também a "natureza" e a "origem", cujo recurso e cuja invocação, respectivamente, não deixam de acenar com uma simulação que pretende "mascarar" o medo da modernidade e "ocultar" um sofisma reacionário, simultaneamente assinalando a vivificação de uma idéia e a fundação de uma História (DUVIGNAUD, 1971, p. 128).

\footnotetext{
A verdadeira inclusão deverá ter como alicerce um processo de construção de consensos (valores, políticas e princípios) proveniente de uma reflexão coletiva sobre o que é escola, quais as suas funções, os seus problemas e a maneira de solucioná-los. Deve-se buscar uma reflexão orientada para o diagnóstico e para a ação, e isso não se limita ao atendimento dos princípios normativos legais que justificam a inclusão. É preciso, (...) adotar a concepção de homem que traça as ações e orienta as formas para pensar na própria integração. (MATTOS, 2002, p. 20, grifos meus)
}

Se a precariedade ou a insuficiência da formação docente no sentido de assegurar a eficiência do atendimento aos educandos portadores de necessidades especiais nas classes comuns se impõe como um dos problemas do sistema de ensino 
em relação à educação inclusiva, torna-se imprescindível um investimento da própria instituição escolar inicialmente no sentido de possibilitar do desenvolvimento da percepção referente às necessidades educacionais especiais à flexibilização da ação pedagógica nas diversas áreas do conhecimento, da avaliação contínua da eficiência do processo educativo à atuação integrada do corpo docente (especificamente do professor especializado), à medida que

(...) a necessidade de recursos humanos devidamente capacitados para atuar em classes inclusivas implica não só o conhecimento a respeito das especificidades da deficiência com a qual se vai trabalhar, mas também uma reflexão crítica acerca do sentido da educação e de suas finalidades. (SERRA, 2006, p. 36).

Nessa perspectiva, pois, caracterizando-se como uma proposta que emerge através de políticas educacionais que convergem para a implementação de um novo paradigma, a educação inclusiva se impõe como um processo que envolve desde o ensino básico até o nível superior, não devendo manter a instituição escolar uma atitude passiva em relação aos alunos especiais, tornando-se apenas uma agência de recepção que, no entanto, não disponibilize os meios necessários para a superação das dificuldades de assimilação dos conteúdos propostos em função do currículo básico, tendo em vista a imprescindibilidade quanto ao desenvolvimento de estratégias de flexibilização, adaptação curricular e práticas alternativas, à medida que demanda, em suma, a conscientização das diferenças humanas, que pressupõe, enfim, um investimento nas potencialidades dos educandos que se sobreponha aos ritos pedagógicos pré-estabelecidos que ignoram a complexidade e heterogeneidade de estilos e ritmos de aprendizagem no processo formativo-educacional, ao qual, a partir de então, cabe uma intervenção que transponha as fronteiras do universal e se detenha, enfim, no múltiplo, na diversidade (MARQUES; MARQUES, 2003, p. 235).

Trazendo como fundamento um jogo diferencial e um contrapondo particular envolvendo distintas dimensões, a toda identidade pessoal ou coletiva se impõe uma relação histórica que as implica, tendendo a diferença à organização plural, que converge para uma verdadeira unidade, à medida que se sobrepõe à unidimensionalidade cultural e ao pretenso dilema entre uma determinada concepção de progresso (científico-tecnológico?) e as especificidades que se the caracterizam no arcabouço social e que, em certo sentido - precisamente aquele que traz como fundamento uma racionalidade que prescinde do aspecto comunicacional, incorporando 
a logicidade instrumental, tanto quanto a objetividade reducionista, que a pressupõe -, relegam as minorias à margem do mundo de significações, práticas e valores compartilhados que perfaz o sentido de uma comunidade, se lhes privando da possibilidade de assegurar os liames de pertencimento efetivo que, inter-relacionando vários aspectos - a saber, social, econômico, político, cultural -, demanda a condição de cidadania no âmbito de um processo (ora designado como "evolutivo") de construção societária que traz como fundamento o sistema educacional e se mantém adstrito ao alinhamento que prioriza certos tipos e grupos privilegiados (DUVIGNAUD, 1971, p. 140).

\section{Referências bibliográficas}

BARAQUIN, N.; LAFFITTE, J. Dicionário de Filósofos (Dictionnaire des Philosophes). Tradução de Pedro Elói Duarte. Coleção Lexis. Lisboa: Edições 70. 2004. 397 p.;

BIBIANO, B. É possível resolver: experiências reais esclarecem dúvidas sobre o trabalho. Revista Nova Escola. p. 49-55. São Paulo: Abril, ago. 2011, 114 p.;

BISPO, J. G. R. Necessidades especiais e trabalho. Jus Navigandi, Teresina, ano 12, n. 1822, 27 jun. 2008. Disponível em: http://jus2.uol.com.br/doutrina/texto.asp?id=11439 >. Acesso em 28 ago. 2010;

BOURDIEU, P. Sociologia. Organizador: Renato Ortiz. Tradução de Paula Montero e Alicia Auzmendi. São Paulo: Ática, 1983, 191 p.;

BRASIL. Ministério da Educação e Cultura. Constituição da República Federativa do Brasil de 1988. Marcos legais. 1988. Disponível em < http://gestao2010.mec.gov.br/marcos_legais/decree_104.php >. Acesso em 1 jun. 2012;

. Ministério da Educação e Cultura. Secretaria de Educação Especial. Marcos Político-Legais da Educação Especial na Perspectiva da Educação Inclusiva. 2008. Disponível em $<\quad$ http://pfdc.pgr.mpf.gov.br/atuacao-e-conteudos-deapoio/publicacoes/educacao/marcos-politico-legais.pdf > . Acesso em 1 jun. 2012;

. Ministério da Previdência e Assistência Social. Lei n⿳0 8.213, de 24 de julho de 1991. Disponível em < http://www.planalto.gov.br/ccivil_03/leis/L8213cons.htm $>$. Acesso em 1 jun. 2012;

BRUNO, M. M. G. Educação Inclusiva: Componente da Formação de Educadores. Revista Benjamin Constant, Rio de Janeiro, Dez. 2007, Ano 13, Número 38. Disponível em $<\underline{\text { http://www.ibc.gov.br/?catid=4\&itemid=10103 }}>$. Acesso em 10 ago. 2010; 
$\mathrm{CAFARDO}^{1} \mathrm{R}$. Inclusão em escolas regulares é polêmica. Convívio de alunos especiais com os demais é parcial no Reino Unido. O Estado de S. Paulo, 2 nov. 2008, A21; ${ }^{2}$, _. MEC defende integração com alunos especiais. O Estado de S. Paulo, 2 nov. 2008, $\overline{\mathrm{A} 2} 1$

CARVALHO, J. S. F. de. A crise na educação como crise da modernidade. Hannah Arendt Pensa a Educação. Hannah Arendt Pensa a Educação 4. Revista Educação Especial: Biblioteca do Professor. São Paulo: Segmento. s/d;

CAVALCANTE, M. Interdisciplinaridade: um avanço na educação. Revista Nova Escola. p. 52-55. São Paulo: Abril, ago. 2004, 65 p.;

CORREIA, L. de M. Dez anos de Salamanca: Portugal e os alunos com necessidades educativas especiais. In: RODRIGUES, D. (Org.). Inclusão e educação: doze olhares sobre a educação inclusiva. São Paulo: Summus, 2006. p. 237-273;

DELEUZE, G. Diferença e repetição. Tradução de Luiz Orlandi e Roberto Machado. 2 ed. revista e atualizada. Rio de Janeiro: Graal, 2006;

DENARI, F. E. Um (novo) olhar sobre a formação do professor de educação especial: da segregação à inclusão. In: RODRIGUES, D. (Org.). Inclusão e educação: doze olhares sobre a educação inclusiva. São Paulo: Summus, 2006. p. 35-63;

DUVIGNAUD, J. A sociologia: guia alfabético. Tradução de Ivan Pedro de Martins. Rio de Janeiro: Forense-Universitária, 1974, 310 p.;

FREITAS, S. N. A formação de professores na Educação inclusiva: construindo a base de todo o processo. In: RODRIGUES, D. (Org.). Inclusão e educação: doze olhares sobre a educação inclusiva. São Paulo: Summus, 2006. p. 161-181;

GADOTTI, M. Paulo Freire, Memória e Presença. Educação/Artigo. Cultura. O Estado de S. Paulo. 27 ma. 2007, D6;

HOFFMANN, J. M. L. Avaliar para promover: as setas do caminho. 6. ed. Porto Alegre: Mediação, 2004;

MACIEL, M. R. C. Portadores de deficiência: a questão da inclusão social. São Paulo em Perspectiva, vol. 14, n. 2, São Paulo: Ab./Jun. 2000. Disponível em < http://www.scielo.br/scielo.php?pid=S0102-

$\underline{88392000000200008 \& \text { script }=\text { sci arttext\&tlng }=\text { en }}>$. Acesso em 22 ago. 2010;

MARQUES, C. A.; MARQUES, L. P. Do Universal ao múltiplo: os caminhos da inclusão. In: LISITA, V. M. S. de S.; SOUSA, L. F. E. C. P. (Orgs.). Políticas educacionais, práticas escolares e alternativas de inclusão escolar. Rio de Janeiro: DP\&A, 2003. p. 223-239;

MARSHALL, T. H. Cidadania, classe social e status. Rio de Janeiro: Zahar, 1967;

MATTOS, E. A. Deficiente mental: integração/inclusão/exclusão. Videtur-13, São Paulo: Salamanca, 2002. p. 13-20. Disponível em: < 
http://www.hottopos.com/videtur13/edna.htm >. Acesso em 1 jun. 2012;

MAZZOTTA, M. J. S. Educação escolar: comum ou especial? São Paulo: Pioneira, 1987 ;

SERRA, D. Inclusão e ambiente escolar. In: SANTOS, M. P.; PAULINO, M. M. (Org.). Inclusão em educação: Culturas, políticas e práticas. São Paulo: Cortez, 2006. p. 3144;

TADEU, T. Tinha horror a tudo que apequenava... Biografia intelectual. Deleuze Pensa a Educação 6. Revista Educação Especial: Biblioteca do Professor. São Paulo: Segmento, s/d, pp. 6-15;

UNESCO. Declaração de Salamanca: Sobre Princípios, Políticas e Práticas na Área das Necessidades Educativas Especiais. 1994. Disponível em < http://portal.mec.gov.br/seesp/arquivos/pdf/salamanca.pdf >. Acesso em 1 jun. 2012. 